\title{
Social Media and Absorptive Capacity of Greek Government Agencies
}

\author{
Euripidis Loukis \\ University of the Aegean \\ eloukis@aegean.gr
}

\author{
Marinos Themistocleous \\ University of Piraeus \\ mthemist@unipi.gr
}

\author{
Efthymia Nikolaou \\ University of the Aegean \\ icsdm14040@aegean.gr
}

\author{
Marina Fragkiskou \\ University of the Aegean \\ icsdm14047@aegean.gr
}

\begin{abstract}
As the external environment of most organizations becomes increasingly dynamic and complex, the exploitation and management of external knowledge becomes of critical importance for their success. This has led to a growing interest of both researchers and practitioners in the study of their absorptive capacity (ACAP). However, the research that has been conducted in this area has focused on the private sector, while there is a lack of similar research for the public sector. This paper contributes to filling this research gap, by investigating the use of social media (SM) in the public sector from the ACAP perspective, examining to what extent SM are used by Greek government agencies for the enhancement of their ACAP. It has been based on interviews with the SM managers of ten Greek government agencies from the central, regional and municipal government. It is concluded that in the examined government agencies SM are used only to a small extent for enhancing their ACAP, making limited exploitation of the potential that $S M$ have for this purpose. In particular, SM are used to some extent for enhancing one of the components of ACAP, the ability for external exploratory learning, but not at all for enhancing the other two critical components of it: the abilities for transformative and exploitative learning.
\end{abstract}

Keywords: social media, absorptive capacity, public sector, government.

\section{Introduction}

As the external environment of most organizations becomes increasingly dynamic and complex, the exploitation and management of external knowledge becomes of critical importance for their success, and this has led to an increasing interest of both researchers and practitioners in the concept of absorptive capacity (ACAP) [5, 7, 8, 18, 41]. Cohen and Levinthal [8] initially defined ACAP as 'the ability to recognize the value of new information, to assimilate it, and apply it to commercial ends'. Zahra and George [41] defined ACAP as a dynamic capability with two main dimensions: 'potential absorptive capacity', which refers to firm's ability to acquire and then assimilate external knowledge, and 'realized absorptive capacity', which refers to firm's ability to transform the assimilated knowledge and then exploit it for the development of innovations in its processes, products and services, and in general for achieving firm's objectives. It is widely recognized that ACAP is a critical determinant of the innovation performance of organizations $[8,18,19,41]$.

The original publications on ACAP by Cohen and Levinthal $[7,8]$ identified three main components of it: i) ability to recognize, acquire and understand potentially valuable new knowledge from outside the firm through exploratory learning; ii) ability to assimilate this valuable new knowledge through transformative learning; and iii) ability to use the assimilated knowledge in order to create new knowledge and commercial outputs through exploitative learning. Subsequently Zahra and George [41] identified the following four components of ACAP: a) acquisition capacity: it is the ability to locate, identify, value and acquire external knowledge that is critical to the operations or/and products and services of the organization; b) assimilation capacity: it is the ability to analyze the new information or knowledge and then process, interpret, understand and classify it; c) transformation capacity: it is the ability to combine/ integrate the newly acquired knowledge in the previous knowledge base of the firm, and to discover novel associations between elements of the continuously enriched knowledge base of the organization, and in general new insights; d) application or exploitation capacity: it is the ability to incorporate acquired, assimilated and transformed knowledge into operations, not only in order to refine, perfect, expand and leverage existing routines, processes, competences and knowledge, but also to create new operations, competences, routines, as well as new products and services. All the above-mentioned previous literature identifying the components of ACAP argues strongly that in order to achieve high levels of innovation 
performance all these ACAP components should be developed; if only the potential ACAP is developed (i.e. abilities for recognition, acquisition and assimilation of useful external knowledge), but not the realized ACAP (abilities for transformation, application and exploitation of this knowledge for the development of innovations in its processes, products and services, and in general for achieving firm's objectives), then the positive impact on innovation and performance will be limited.

Most of the research that has been conducted concerning the ACAP focuses on the private sector, investigating the determinants, the mechanisms and the outcomes of firms' ACAP (see section 2.1 for a brief review of relevant literature), while there is a lack of similar research for the public sector. However, it is widely recognized that the public sector faces a rapidly changing social and economic environment, with new problems and needs continuously arising, while at the same time the 'traditional' problems and needs government has been dealing with for long time continuously change and become more complex, multidimensional and 'wicked'; these necessitate extensive acquisition of relevant external knowledge and exploitation of it for making innovations in the policies, services and internal processes and operations of the public sector $[10,11,12]$. Therefore, it is highly beneficial to conduct research on the ACAP of government agencies, in order to create knowledge about its organizational and technological determinants, its mechanisms and its outcomes, which will enable the improvement of public sector ACAP and finally innovation capacity.

This paper contributes to filling the above research gap by i) investigating to what extent an emergent trend in the public sector, the use of social media (SM) by government agencies, is exploited for the enhancement of their ACAP (and in particular for the enhancement of its abovementioned important individual components); and ii) formulating proposals for improvements in this direction (i.e. for a better exploitation of SM by government agencies for the enhancement of their ACAP). So our main research questions are:

- 'To what extent are SM used for the enhancement of government agencies' ACAP?'

- 'How can we exploit better SM in government for the above purpose?'

For addressing these research questions we use as foundation a typology of SM use by organizations, proposed by $\mathrm{Hu}$ and Schlagwein [14] and Schlagwein and $\mathrm{Hu}$ [36], which includes five types of SM use (broadcast, dialogue, collaboration, knowledge management and sociability - each of them can be external or internal), that have been associated with the support of specific components of the ACAP (exploratory, transformative or exploitative learning).
By examining to what extent each of these SM use types is employed by government agencies, we gain useful insights concerning the extent of use of SM for the enhancement of the individual components of their ACAP.

Our study has been based on interviews with the SM managers of ten Greek government agencies from the central, regional and municipal government. This is an interesting national context, as it is characterized by:

a) A culture of lower propensity for innovation; according to the European Innovation Scoreboard 2015 (http://ec.europa.eu/growth/industry/innovation/factsfigures/scoreboards/index_en.htm), Greece belongs to the third out of the four categories of European countries as to their innovation performance defined by this scoreboard, being characterized as a 'moderate innovator'. So it is highly interesting to examine to what extent in this 'innovation averse' national context the SM are used for enhancing this critical for government innovation ACAP.

b) A long economic crisis (since 2009), which has resulted in huge losses of country's GDP, employment and consumption [27], causing a lot of changes and problems in the Greek economy and society, making their 'traditional' problems and needs more acute, and at the same time giving rise to new problems and needs. So it is highly beneficial to examine to what extent Greek government agencies are using SM in order to acquire knowledge from their external environment about the above big changes, problems and needs, and then assimilate and exploit this knowledge for making the required innovations in their policies and services in order to adapt to this new situation.

c) Chronic pathologies of the public sector, which result in low quality of services to citizens and firms and at the same time high operating costs $[21,26]$. So it is interesting to examine to what extent Greek government agencies use SM in order to collect know-ledge from their external environment about weaknesses of the services they provide to citizens and firms, and proposals for their improvement, and then exploit this knowledge for making changes and innovations.

Our paper consists of five sections. This introductory section is followed by section 2 outlining the background of our study, which consists of previous literature on ACAP and on SM use in government. Then in section 3 the method and data of our study are described, while in section 4 the results are presented. Finally, section 5 summarizes the conclusions.

\section{Background}

\subsection{Determinants of Absorptive Capacity}

The critical importance of the ACAP for the 
innovation performance of organizations in the highly dynamic and complex modern economic and societal contexts has motivated some empirical research for the identification of organizational and technological factors that affect ACAP; however, this research focuses on the ACAP of private sector firms. With respect to the former, the original publication on ACAP by Cohen and Levinthal [8] identifies the conduct of research and development (R\&D) as the central determinant of ACAP, as it increases the knowledge stock of the firm, which enables the identification and absorption of new relevant knowledge from the external environment. They also identified some additional organizational determinants of ACAP, which are associated with the internal communication structure: the existence of 'gate-keepers/boundary-spanners' (who monitor the external environment, identify knowledge useful for the firms and 'translate' it into a form understandable by firm's employees), a shared - language among firm's employees and also cross-functional interfaces and communication. In [16] and [40] are identified two more types of organizational mechanisms that increase the ACAP: the first are associated with coordination (crossfunctional inter-faces, participation in decision making and job rotation), and the second with employees' socialization (development of shared language, values and goals). Recently [9] identified some additional organizational characteristics that increase ACAP: slack resources, tolerance for failure, willing-ness to cannibalize and external openness.

With respect to the technological determinants of ACAP, there has been some empirical research concerning the effects of some characteristics of firm's information and communication technologies (ICT) infrastructure on its ACAP. [20] concludes that the flexibility of firm's ICT infrastructure (i.e. high levels of connectivity between its components, compatibility/ data sharing ability among them and modularity) and the assimilation of ICT (i.e. high level of using ICT applications in firm's business processes, functional areas and management) affect positively its ACAP, as well as its supply chain agility, and through them finally firm's performance. [17] has found that the use of ICT for the provision of integrated market related information to employees increase their relevant ACAP. [4] has concluded that the mastery of technical ICT skills and the use of ICT in interdependent tasks affect positively ACAP, which in turn enhances firm's performance. Recently [15] investigated the use of franchisors' ICT infrastructure by franchisees as a learning mechanism, and concluded that it affects positively the effectiveness of knowledge transfer from the franchisors to the franchisees, the ACAP of the latter, and finally their financial performance. Also, [34] examines the effects of an ICT related variable, the data integration (defined as the provision to firm's employees of the capability of integrated access to customers, partners, industry and market data), and an organizational variable, the connectedness (defined as culture of communication and exchange of knowledge among employees across functional units and hierarchical levels), on ACAP; he concludes that both variables affect ACAP positively.

An interesting review of previous research concerning the association between ACAP and ICT is presented in [35], which has led to the development of research hypotheses concerning the effects of specific ICT capabilities, in combination with specific organizational capabilities, on different components of the ACAP: a) Synergies arising from complementarities between 'outside-in' ICT capabilities (i.e. outwards focused ICT enabling the collection of knowledge from the external environment) and internal knowledge exchange related capabilities will have a positive effect on a firm's ability to identify and recognize the value of external knowledge; b) Synergies arising from complementarities between 'spanning' ICT capabilities (i.e. inwards-focused ICT enabling storing, archiving, retrieving and sharing of knowledge within the firm) and internal knowledge exchange related coordination and socialization capabilities will have a positive effect on a firm's ability to assimilate and transform external knowledge; c) Synergies arising from complementarities between 'inside-out' ICT capabilities (i.e. inwards-focused ICT enabling the design and production of products and services for firm's external environment) and knowledge exchange related socialization capabilities will have a positive effect on a firm's ability to apply external knowledge.

However, limited research has been conducted concerning the effects of SM use by organizations on their ACAP. There is only one field study of 20 Australian firms described in [14] and [36], which has developed:

A) A typology of SM use by organizations, which includes five types of SM use: i) broadcast (use of SM for the uni-directional broadcasting of information); ii) dialogue (use of SM for multi-directional dialogue and communication); iii) collaboration (use of SM in order to facilitate the creation of a particular solution, product or service); iv) knowledge management (use of SM for the storage, maintenance and retrieval of knowledge); and v) sociability (use of SM for generating fellowship, loyalty and social relations). Furthermore, this typology distinguishes between external environment oriented application of the above five SM use types, and also internal application of them (e.g. based on Yammer, which is an internal social media platform increasingly used by firms [31]). It is concluded that both of them can be very useful for the enhancement of ACAP. 
B) Some theoretical propositions associating the above types of SM use with the support of three main components of the ACAP [18, 41], which concern abilities for exploratory learning (searching, understanding, recognizing and acquiring knowledge), transformative learning (interpreting, assimilating, maintaining and reactivating knowledge) and exploitative learning (applying, exploiting and maximizing impact of knowledge); these associations are shown in detail in Table 1, as we them in this study (see section 3).

\begin{tabular}{|c|c|c|}
\hline $\begin{array}{c}\text { Type of SM } \\
\text { Use }\end{array}$ & External & Internal \\
\hline Broadcast & & $\begin{array}{c}\text { Exploratory } \\
\text { Learning }\end{array}$ \\
\hline Dialogue & $\begin{array}{c}\text { Exploratory } \\
\text { Learning }\end{array}$ & $\begin{array}{c}\text { Transformative } \\
\text { Learning } \\
\text { Exploitative } \\
\text { Learning }\end{array}$ \\
\hline Collaboration & & $\begin{array}{c}\text { Exploitative } \\
\text { Learning }\end{array}$ \\
\hline Knowledge & & $\begin{array}{c}\text { Transformative } \\
\text { Learning }\end{array}$ \\
\hline Management & & \\
\hline Sociability & & \\
\hline
\end{tabular}

Table 1. Associations of SM use types with ACAP components

However, there is a lack of similar research for the public sector. It is therefore necessary to exploit the research that has been conducted on the organizational and technological determinants of ACAP in the private sector, possibly making appropriate adaptations in order to take into account the specificities of the public sector context, in order to create knowledge concerning the determinants of the ACAP of government agencies (since, as mentioned in the Introduction, government agencies experience a highly dynamic social and economic environment, leading to rapid changes in the problems and needs they have to address, so it is necessary to improve their ACAP). Our study contributes to filling this research gap, investigating to what extent SM are exploited by government agencies for the enhancement of their ACAP.

\subsection{Social Media Use in Government}

The increasing exploitation of SM in the public sector has attracted considerable research interest in this relatively new phenomenon. One stream of this research is dealing with the potential of SM use by government agencies, and the opportunities it provides; some representative studies of this research stream are reviewed next. [39] argueS that SM constitute a 'tectonic' technological shift, which is going to have strong and multi-dimensional effects on government structure and operation. These social platforms can drive a transition from monolithic government to 'Government 2.0', in which pluralistic, networked forms of government called "governance webs" (or gwebs) become the dominant organizational model for service delivery and policy-making; this term denotes digitally enabled networks of public, private and/or civil society participants, which perform activities that previously were the exclusive domain of single public agencies. [6] is dealing with the potential of SM for transforming the political domain in general. In particular, he elaborates the basic principles of web 2.0 based politics and suggests the following research directions: "the Internet as a platform for political discourse; the collective intelligence emergent from political Web use; the importance of data over particular software and hardware applications; experimentalism in the public domain; the creation of small scale forms of political engagement through consumerism".

[2] and [3] identify a set of opportunities that SM offer to government agencies, and then classify them into three main groups: i) democratic participation and engagement (use of SM to engage the public in government policy making, fostering participatory dialogue and providing to more citizens' groups a voice in discussions of policy development and implementation), ii) public services co-production (governments and the public jointly develop, design, and deliver government services using the SM, aiming to improve service quality, delivery, and responsiveness), iii) crowdsourcing solutions and innovations (seeking innovation by exploiting public knowledge and talent through SM-based interaction, in order to develop innovative solutions to big societal problems). [29] conclude that SM offers to government agencies important opportunities to communicate with their constituents and to reinvent government-citizen relationships; they summarize the benefits of the use of $\mathrm{SM}$ in governments in "efficiency, user convenience, transparency, accountability, citizen involvement, and improved trust and democracy".

In general, this research stream categorizes the potentials of SM use by government into two main types: information provision to citizens and interaction with them. The former includes the one-directional use of SM in order to disseminate information for enhancing government outreach and improving government transparency; the latter includes the bi-directional use of $\mathrm{SM}$ in order to interact with various internal and external stakeholders, promote citizens' participation in decisionmaking and improve communication and collaboration 
between government and citizens as well as among government agencies internally.

A second stream of research is dealing with the real use of SM in the public sector; we review some representative studies of this research stream next. [23] concludes that government is focusing mostly on using $\mathrm{SM}$ as one-way communication channels in order to push out information, mainly recycled from other government communication channels, rather than using them as two-way communication and interaction channels for various citizens' engagement activities. The same study finds that government agencies have a limited interest to create a direct, reciprocated relationship with citizens by having with them creative conversations online. [24] examines the use of social networks and other interactive tools in the 75 largest U.S. cities and further analyze discussions on social networks; they conclude that one-way "push" strategies predominate, although there are some signs of greater openness toward dialog with citizens. [13] explores how successfully German local governments use SM for managing external communications with citizens. They conclude that the online communication of local governments in Germany aims mainly at disseminating information in a traditional way, without adapting their communication habits to the particular characteristics of social media. [32], based on evidence collected through a survey of US local governments, conclude that SM media are used mainly for one-way communication, so they do not appear to be pushing and moving local governments in the direction of Web 2.0 (with the authors stating that perhaps there is a movement in the direction of 'Web 1.5').

On the contrary [37], examining the use of SM by the US Executive, find that SM are widely used as mechanisms in order both to disseminate information out to the public, and also to increase public participation, encourage user engagement and solicit feedback and insight from citizens. Also, [38] analyze five central SM initiatives of the Greek government aiming to promote openness and transparency, as a strategic response to the increasing citizens' distrust of the government and the whole political system due to the ongoing economic crisis. They conclude that these central SM initiatives have provided significant benefits: they have provided a space to government and citizens to interact and collaborate, enabling the exchange of information and knowledge, ideas on planning, and further information and knowledge sharing across citizens for entrepreneurial activities.

In general, this second research stream concludes that the main use of SM by government agencies is for one-way communication with citizens, in order to provide information to them. However, some studies of this second research stream have found that SM are also used - to a lower extent - by government for two-way communication/interaction with citizens as well.

Our study makes a contribution to this second research stream, by examining the real use of SM by government agencies from an important perspective that has not been examined by previous literature: the ACAP perspective; we examine to what extent SM are used by government for enhancing this highly important capacity for their adaptation and innovation in the modern dynamic and complex environment.

\section{Method and Data}

In order to investigate to what extent Greek government agencies exploit SM for enhancing their ACAP we have used as our foundation the research of $\mathrm{Hu}$ and Schlagwein [14] and Schlagwein and $\mathrm{Hu}$ [36]. This research, as explained in more detail in section 2.1, has developed a typology of SM use by organizations, including five SM use types (broadcast, dialogue, collaboration, knowledge management and sociability each of them can be external or internal), which have been associated with support of specific components of the ACAP (exploratory, transformative and exploitative learning). So we examine to what extent and how each of the above SM use types is actually employed by Greek government organizations, and this allows us to gain useful insights concerning the use of SM for the enhancement of the individual components of their ACAP. Therefore, our 'analytical framework' [30], which is shown in Table 2, includes as main elements:

- the analysis of the extent and the ways of external and internal utilization of these five SM use types by Greek government agencies,

- and additionally the analysis of the existing mechanisms (technological or organizational) of internal exploitation of the information collected from the citizens through government agencies' external SM, as these mechanisms are highly important for the ACAP.

For the collection of data, we used a combination of both qualitative and quantitative techniques. Qualitative techniques allow a more in-depth examination of a phenomenon of interest, and therefore lead to the generation of deeper knowledge about it, not limited to a predefined number of variables (as in the quantitative techniques), enabling a better and richer understanding of it; at the same time the quantitative techniques offer the advantage of enabling the summarization of a large quantity of evidence into a few numbers (e.g. averages or relative frequencies), which makes it easier to draw conclusions [22, 30]. So we have exploited the advantages and strengths of both qualitative and quantitative techniques for addressing our research questions. 
To what extent and how your government agency uses:

- external social media for broadcast/dissemination of various kinds of information to citizens

- internal social media for broadcast/dissemination of various kinds of information to your employees

- external social media for bi-directional dialogue and consultation with citizens

- internal social media for bi-directional internal dialogue and consultation among your employees

- external social media for collaboration with citizens (or specific groups of citizens) for the development of specific policies or services, or improvements of existing ones, or for finding solutions to specific problems

- internal social media for internal collaboration among your employees (or specific groups of employees) for the development of specific policies or services, or improvements of existing ones, or for finding solutions to specific problems

- external social media for supporting the collection of useful knowledge and ideas from citizens concerning your (existing or under development) policies and services (e.g. strengths, weaknesses, proposed improvements), or relevant new needs

- internal social media for supporting the storage, search, retrieval and exploitation of useful knowledge and ideas among your employees

- external social media for enhancing social relations, mutual understanding and trust with citizens

- internal social media for enhancing social relations, mutual understanding and trust among your employees

What are your main mechanisms of internal exploitation of the information collected from the citizens through government agencies' external SM?

\section{Table 2. Analytical framework of our study}

In particular, following the 'elite inter-viewing' approach proposed in [33], we conducted interviews with the SM managers of ten Greek government agencies from all three layers of it: four from the central government, three from the regional government and three from the municipal government. The above individuals (higher rank public servants or advisors of the top elected official) have a good and complete knowledge concerning the use of SM in their government agencies, so they are the most appropriate ones for providing to us the information required for this study. Each of these interviews had a duration of 1-1.5 hours, and included initially a semi-structured qualitative discussion on the eleven elements/questions of our analytical framework (shown in Table 2), which aimed to provide a deeper and richer understanding of the extent and the ways of employing these types of SM use in the particular government agency. Then the interviewee was asked to fill a questionnaire, which consists of ten questions concerning the extent of utilizing the ten SM use types included in our analytical framework, to be answered in a five-levels scale $(1=$ not at all, $2=$ to a small extent, $3=$ to a moderate extent, 4 $=$ to a large extent, $5=$ to a very large extent); each of these responses aims to condense/summarize the qualitative information provided in the discussion concerning the utilization of the particular SM use type.
All the above qualitative discussions were recorded (with the consent of the interviewees), and then transcribed and coded manually using an open coding approach [22]. The data collected through the questionnaire were processed using Excel.

\section{Results}

In Table 3 we can see for each of the examined government agencies of the central government (CG1CG4), the regional government (RG1-RG3) and municipal government (MG1-MG3), the extent of utilization of the abovementioned ten SM use types, based on the combination of the qualitative data we collected through the interviews and the quantitative data we collected through the questionnaire.

We can see that the most extensively utilized one is the external broadcast, with eight out of the ten examined government agencies using it to a very large extent (VLE) or large extent (LE) (and all four examined central government agencies are using it to a very large extent); one regional government is using it to a small extent (SE), and another one is not using SM at all (N).

In the qualitative discussions it has been mentioned by the interviewees (and this has been confirmed by examining the SM accounts of the corresponding 
government agencies) that SM are used as a low cost and wide reach channel in order to disseminate to the citizens information about their activities and services, and also speeches and initiatives of the top elected officials. Furthermore, the examined regional and municipal government agencies use extensively their $\mathrm{SM}$ in order to disseminate information about local cultural events or social activities of various local communities

The second most extensively utilized SM use type is the external bi-directional dialogue and consultation with citizens, with five out of the ten examined government agencies using it to a very large or large extent, and another one using it to a moderate extent (ME); we remark that the larger central and regional government agencies are using it more than the smaller municipal government agencies. In the qualitative discussions most of the interviewees mentioned that SM problems), with four government agencies using the former, and two using the latter, to a very large or large extent.

On the contrary, quite limited is the utilization of the internal SM use types by the examined government agencies. Though there was some awareness of internal social media (such as Yammer [31]), most of them have not taken some steps in this direction, having as main priority the external SM, as they are oriented towards the citizens and the society; some expressed skepticism as to the compatibility of internal SM with the culture of their employees, and public servants in general. Only one examined municipality has an internal ecollaboration platform (based on the 'Comidor' enterprise collaboration software), which is used for internal information dissemination, dialogue, collaboration, knowledge management and socialization.

\begin{tabular}{|c|c|c|c|c|c|c|c|c|c|c|}
\hline & $\begin{array}{c}\text { External } \\
\text { Broadcast }\end{array}$ & $\begin{array}{c}\text { Internal } \\
\text { Broadcast }\end{array}$ & $\begin{array}{l}\text { External } \\
\text { Dialogue }\end{array}$ & $\begin{array}{l}\text { Internal } \\
\text { Dialogue }\end{array}$ & $\begin{array}{c}\text { External } \\
\text { Collab. }\end{array}$ & $\begin{array}{l}\text { Internal } \\
\text { Collab. }\end{array}$ & $\begin{array}{c}\text { External } \\
\text { Kn. } \\
\text { Man. }\end{array}$ & $\begin{array}{c}\text { Internal } \\
\text { Kn. } \\
\text { Man. }\end{array}$ & $\begin{array}{c}\text { External } \\
\text { Social. }\end{array}$ & $\begin{array}{c}\text { Internal } \\
\text { Social. }\end{array}$ \\
\hline CG1 & VLE & VLE & VLE & SE & SE & $\mathrm{N}$ & LE & $\mathrm{N}$ & $\mathrm{N}$ & $\mathrm{N}$ \\
\hline CG2 & VLE & $\mathrm{N}$ & $\mathrm{N}$ & $\mathrm{N}$ & $\mathrm{N}$ & $\mathrm{N}$ & $\mathrm{ME}$ & $\mathrm{N}$ & $\mathrm{N}$ & $\mathrm{N}$ \\
\hline CG3 & VLE & $\mathrm{N}$ & $\mathrm{ME}$ & $\mathrm{N}$ & SE & $\mathrm{N}$ & $\mathrm{N}$ & $\mathrm{N}$ & $\mathrm{N}$ & $\mathrm{N}$ \\
\hline CG4 & VLE & $\mathrm{N}$ & VLE & $\mathrm{N}$ & VLE & $\mathrm{N}$ & VLE & $\mathrm{N}$ & $\mathrm{N}$ & $\mathrm{N}$ \\
\hline RG1 & $\mathrm{N}$ & $\mathrm{N}$ & $\mathrm{N}$ & $\mathrm{N}$ & $\mathrm{N}$ & $\mathrm{N}$ & $\mathrm{N}$ & $\mathrm{N}$ & $\mathrm{N}$ & $\mathrm{N}$ \\
\hline RG2 & VLE & $\mathrm{N}$ & LE & $\mathrm{N}$ & LE & $\mathrm{N}$ & LE & $\mathrm{N}$ & $\mathrm{N}$ & $\mathrm{N}$ \\
\hline RG3 & LE & SE & LE & SE & SE & SE & SE & SE & SE & $\mathrm{N}$ \\
\hline MG1 & SE & $\mathrm{N}$ & SE & SE & SE & $\mathrm{N}$ & SE & SE & $\mathrm{N}$ & $\mathrm{N}$ \\
\hline MG2 & VLE & VLE & SE & VLE & SE & VLE & VLE & VLE & VLE & VLE \\
\hline MG3 & LE & $\mathrm{N}$ & LE & $\mathrm{N}$ & $\mathrm{N}$ & $\mathrm{N}$ & $\mathrm{N}$ & $\mathrm{N}$ & $\mathrm{N}$ & $\mathrm{N}$ \\
\hline
\end{tabular}

Table 3. Extent of utilization of the ten SM use types by the examined government agencies

can be a good source of useful information and feedback from the citizens, e.g. about problems in existing services or infrastructures (the latter being very important for municipalities and regional governments), suggestions for improvements, etc. However, it has been mentioned that some 'moderation' is required, in order to 'filter out' insulting and inappropriate postings sometimes entered by some citizens.

The external knowledge management (meant as collection of knowledge and ideas from citizens) follows, and then the external collaboration with citizens (for the development/improvement of specific policies or services, or finding solutions to specific
The above findings are in agreement with the conclusions of the second research stream on SM, which has been reviewed in section 2.2: the main use of the SM by the examined Greek government agencies is for oneway communication with citizens in order to disseminate information to them; however, SM are also used - to a lower extent - for two-way communication and interaction with citizens as well. This latter use aims mainly at having dialogue with the citizens, and at the collection of knowledge and ideas from them, and much less at a more substantial collaboration with them for the development/improvement of specific policies or services, or for finding solutions to specific problems. 
Furthermore, with respect to the enhancement of the ACAP, we see that only one of the five SM use types that have a potential to support it (according to previous research of $\mathrm{Hu}$ and Schlagwein [14] and Schlagwein and $\mathrm{Hu}$ [36], as explained in more detail in section 2.1) is utilized to a good extent by the examined Greek government agencies: the external dialogue, which can enhance the external exploratory learning ability (i.e. the ability to recognize, acquire and understand potentially valuable new external knowledge). On the contrary, there is quite limited utilization of the other four internal SM use types that according to the abovementioned previous research have the potential to enhance one or more components of ACAP: for internal broadcast (that can enhance exploratory learning ability), for internal dialogue (that can enhance external transformative and exploitative learning abilities), for internal collaboration (that can enhance exploitative learning ability) and for internal knowledge management (that can enhance transformative learning ability). Therefore, the potential of SM for supporting the enhancement of ACAP is exploited to a small extent: only to some extent for the enhancement of the ability for explorative learning, but not for the enhancement of the highly important abilities for transformative and exploitative learning.

Finally, the main mechanism of internal dissemination and exploitation of the information collected from the citizens through government agencies' external SM we identified in the interviews is forwarding the most important of them to the competent units, in order mainly to reply (so that citizens do not have negative feelings that nobody cares with what they post in social media), and also take necessary actions, solve the problems mentioned by citizens and make improvements of services. This happens in five out of the ten examined government agencies; in another one this information is forwarded to the Minister's Office, which decides for the next steps. Only in the abovementioned municipality, which has an internal ecollaboration platform, it is used for the internal dissemination and discussion of information collected through their external SM. In the remaining government agencies there is no systematic mechanism for this.

\section{Conclusions}

Most organizations today experience an increasingly dynamic and complex environment, and this makes the acquisition, management and exploitation of external knowledge of critical importance for their success, so it is highly important to develop their ACAP. However, the research that has been conducted in this area has focused on the private sector, investigating the determinants, both organizational and technological, the mechanisms and the outcomes of firms' ACAP, while there is a lack of similar research for the public sector. This paper contributes to filling this research gap, by investigating the use of SM in the public sector from the ACAP perspective, examining to what extent SM are used by Greek government agencies for the enhancement of their ACAP.

Our findings indicate that the examined Greek government agencies, experiencing a national context of a long economic crisis, and lower propensity for innovation, use only to a small extent SM for enhancing their highly important ACAP, making a limited exploitation of the potential that SM have for this purpose. In particular, they are using to some extent external SM for enhancing only one of the components of their ACAP: their external exploratory learning ability. However, they are not exploiting the potential of internal SM for enhancing the other two highly important components of their ACAP: their transformative and exploitative learning abilities. Furthermore, there is a lack of effective mechanisms for internal dissemination and exploitation of the information collected from the citizens through their external SM. A possible explanation for the above might be the lower propensity for internal knowledge sharing of the public sector in comparison with the private sector, and in general the lack of such culture and tradition ([1], [28]). The above are quite problematic, since, as mentioned in the Introduction, previous ACAP literature argues that in order to achieve high levels of innovation performance it is necessary to develop all the components of ACAP.

Our study has important implications for both research and practice. With respect to research it opens up new directions of research on an important trend in the public sector, the use of SM, from a highly important new perspective, the enhancement of ACAP, beyond the two main perspectives employed by previous relevant literature (dissemination of information and interaction with citizens). Also, it addresses the issue of appropriate conceptualizations of the different ICT in relevant research, which has been debated for long time (e.g. see [25]), by using for the public sector a comprehensive conceptualization of SM, which has been initially developed and used in the private sector, and includes ten different types of ICT use. This conceptualization can be very useful for the extensive future research required concerning the use of SM in the public sector. Also, our study opens up new directions of research on government agencies ACAP, which is quite important (due to the increasing dynamism and complexity of modern societies and economies), but at the same time might be problematic (due to the abovementioned lack of internal knowledge sharing propensity, culture and tradition of government agencies, which might impact negatively important components of ACAP, which 
concern the internal dissemination, assimilation, transformation and application/ exploitation capacities).

With respect to practice, our study provides useful directions for a better exploitation of SM by government agencies, which can contribute to the enhancement of their ACAP. In particular, our findings indicate that the adoption of external SM should be combined with internal SM as well, possibly in combination with other technological and organizational mechanisms, in order to support the dissemination, assimilation, transformation, application and exploitation of the valuable knowledge acquired from citizens through the external SM. Government agencies, in order to provide substantial support for the development of their ACAP, should use internal SM for the following four purposes: internal broadcast, internal dialogue, internal collaboration and internal knowledge management.

Our study has two main limitations. The first one is that it is based on data collected from only one country, Greece, which as mentioned in the introduction has some specific characteristics (culture of lower propensity for innovation, economic crisis, chronic pathologies of the public sector); so it is necessary to conduct similar research in various types of national contexts, in order to examine to what extent our findings are generalizable. The second limitation is that we have used a combination of both qualitative and quantitative techniques, however the latter include only some basic processing of quantitative data collected from the ten government agencies in which we conducted interviews; so it would be interesting to collect more quantitative relevant data from a larger number of government agencies, and make more advanced processing of them, so that more extensive and generalizable conclusions can be drawn.

\section{References}

[1] Amayah, A. T. "Determinants of knowledge sharing in a public sector organization", Journal of Knowledge Management, 17(3), 2013, pp. $454-471$.

[2] Bertot, J. C., P. T. Jaeger, and D. Hansen, "The impact of policies on government social media usage: Issues, challenges and recommendations", Government Information Quarterly, 29, 2012, pp. 30-40.

[3] Bertot, J. C., P. T. Jaeger, S. Munson, and T. Glaisyer, "Engaging the public in open government: The policy and government application of social media technology for government transparency", IEEE Computer, 43(11), 2010, pp. $53-59$.

[4] Bolívar-Ramos, M. T., V. J. García-Morales, and R. Martín-Rojas, "The effects of Information Technology on absorptive capacity and organizational performance",
Technology Analysis \& Strategic Management, 25(8), 2013, pp. 905-922.

[5] Camisón, C. and B. Forés, "Absorptive Capacity: New Insights for Its Conceptualization and Measurement", Journal of Business Research, 63(7), 2010, pp. 707-715.

[6] Chadwick, A., "Web 2.0: New Challenges for the Study of E-Democracy in an Era of Informational Exuberance". I/S: A Journal of Law and Policy for the Information Society, 5 (1), 2009, pp. 9-41.

[7] Cohen, W. M. and D. A. Levinthal, "Innovation and Learning: The Two Faces of R\&D”, Economic Journal, 99(397), 1989, pp. 569-596.

[8] Cohen, W. M. and D. A. Levinthal, "Absorptive Capacity: A New Perspective on Learning and Innovation", Administrative Science Quarterly, 35(1), 1990, pp. 128-152.

[9] De Araújo Burcharth, A. L. L., C. Lettl, and J. P. Ulhøi, "Extending organizational antecedents of absorptive capacity: Organizational characteristics that encourage experimentation", Technological Forecasting \& Social Change, 90, 2015, pp. 269-284.

[10] European Commission, "Powering European Public Sector Innovation: Towards A New Architecture", Report of the Expert Group on Public Sector Innovation, 2013.

[11] Ferro, E., E. Loukis, Y. Charalabidis, and M. Osella, "Policy Making 2.0: From Theory to Practice", Government Information Quarterly, 30(4), 2013, pp. 359-368.

[12] Head, B. W., "Wicked Problems in Public Policy", Public Policy, 3(2), 2008, pp. 101-118.

[13] Hofmann, S., D. Beverungen, M. Räckers, and J. Becker, What makes local governments' online communications successful? Insights from a multi-method analysis of Facebook. Government Information Quarterly, 30(4), 2013, pp. 387-396.

[14] Hu, M. and D. Schlagwein, "Why Firms Use Social Media: An Absorptive Capacity Perspective", European Conference on Information Systems (ECIS) 2013, 2013 June 5-8, Utrecht.

[15] Iyengar, K., J. R. Sweeney, and R. Montealegre, "Information Technology Use as a Learning Mechanism: The Impact of IT Use on Knowledge Transfer Effectiveness, Absorptive Capacity, and Franchisee Performance", MIS Quarterly, 39(3), 2015, pp. 615-641.

[16] Jansen, J. J. P., F.A.J. Van Den Bosch, and H. W. Volberda, "Managing potential and realized absorptive capacity: how do organizational antecedents matter?", Academy of Management Journal, 48, 2005, pp. 999-1015.

[17] Jimenez-Castillo, D. and M. Sanchez-Perez, "Nurturing employee market knowledge absorptive capacity through 
unified internal communication and integrated information technology", Information \& Management, 50, 2013, pp. 7686.

[18] Lane, P. J., B. R. Koka, and S. Pathak, "The Reification of Absorptive Capacity: A Critical Review and Rejuvenation of the Construct", Academy of Management Review, 31(4), 2006, pp. 833-863.

[19] Leal-Rodríguez, A. L., J. A. Ariza-Montes, J. L. Roldán, and A. G. Leal-Millán, "Absorptive capacity, innovation and cultural barriers: A conditional mediation model", Journal of Business Research, 67(5), 2014, pp. 763-768.

[20] Liu, H., W. Ke., K. K. Wei, and Z. Hua, "The impact of IT capabilities on firm performance: The mediating roles of absorptive capacity and supply chain agility", Decision Support Systems, 54, 2013, pp. 1452-1462.

[21] Makrydimitris, A. and N. Michalopoulos., Reports of Experts on Public Administration 1950-1998, Papazisis Publications (in Greek), Athens, 2000.

[22] Maylor, H. and K. Blackmon, Researching Business and Management, Palgrave-Macmillan, New York, USA, 2005.

[23] Mergel, I., "A framework for interpreting social media interactions in the public sector", Government Information Quarterly, 30(4), 2013, pp. 327-334.

[24] Mossberger, K., Y. H. Wu, and J. Crawford, "Connecting citizens and local governments? - Social media and interactivity in major U.S. cities", Government Information Quarterly, 30(4), 2013, pp. 351-358.

[25] Orlikowski, W. J. and C. S. Iakono, "Research commentary: Desperately seeking the 'IT' in IT research - A call to theorizing the IT artifact", Information Systems Research, 12(2), 2001, pp. 121-134.

[26] Papadopoulos, T., T. Stamati, M. Nikolaidou, and D. Anagnostopoulos, "From Open Source to Open Innovation practices: A case in the Greek context in light of the debt crisis", Technological Forecasting and Social Change, 80, 2013, pp. 1232-1246.

[27] Papageorgiou, A., European Integration in the Age of Narcissism: An Approach of the Greek Economic Crisis', Procedia Economics and Finance, 33, 2015, pp. 129-141.

[28] Pee, L. G. and A. Kankanhalli, "Interactions among factors influencing knowledge management in public-sector organizations", Government Information Quarterly, 33, 2016, pp. 188-199.
[29] Picazo-Vela, S., I. Gutierrez-Martinez, and L. F. LunaReyes, "Understanding risks, benefits, and strategic alternatives of social media applications in the public sector", Government Information Quarterly, 29(4), 2012, pp. 504-511.

[30] Ragin, C. and L. Amoroso, Constructing Social Research - The Unity and Diversity of Method. Sage Publications, 2011.

[31] Rao, L., Yammer Debuts a Facebook for the Enterprise, http://techcrunch.com/2010/09/28/yammer-debuts-afacebook -for-the-enterprise/, 2010

[32] Reddick, C. G. and D. F. Norris, "Social media adoption at the American grass roots: Web 2.0 or 1.5?", Government Information Quarterly, 30, 2013, pp. 498-507.

[33] Richards, D., "Elite interviewing: Approaches and pitfalls", Politics, 10(3), 1996, pp. 199-204.

[34] Roberts, N. "Absorptive capacity, organizational antecedents, and environmental dynamism", Journal of Business Research, 68(11), 2015, pp. 2426-2433.

[35] Roberts, N., P. S. Galluch, M. Dinger, and V. Grover, "Absorptive capacity and information systems research: Review, synthesis, and directions for future research", MIS Quarterly, 36(2), 2012, pp. 625-648.

[36] Schlagwein, D. and M. Hu, "How and why organisations use social media: five use types and their relation to absorptive capacity" Journal of Information technology (forthcoming), 2016.

[37] Snead, J. T. "Social media use in the U.S. Executive branch", Government Information Quarterly, 30, 2013, pp. 56-63.

[38] Stamati, T., T. Papadopoulos, and D. Anagnostopoulos, "Social media for openness and accountability in the public sector: Cases in the Greek context", Government Information Quarterly, 32, 2015, pp. 12-29.

[39] Tapscott, D., A. D. Williams, and D. Herman, "Government 2.0: Transforming Government and Governance for the Twenty- First Century", nGenera Corporation, 2008.

[40] Van den Bosch, F. A. J., H. W. Volberda, M. De Boer, "Coevolution of firm absorptive capacity and knowledge environment: organizational forms and combinative capabilities", Organ. Sci. 10, 1999, pp. 551-568.

[41] Zahra, S. A. and G. George, Absorptive Capacity: A Review, Reconceptualization, and Extension. Academy of Management Review, 27(2), 2002, pp. 185-20. 